\title{
Manufacturing of biodegradable polyurethane scaffolds based on polycaprolactone using a phase separation method: physical properties and in vitro assay
}

\author{
This article was published in the following Dove Press journal: \\ International Journal of Nanomedicine \\ 17 October 2011 \\ Number of times this article has been viewed
}

\author{
Azadeh Asefnejad' \\ Mohammad Taghi Khorasani \\ Aliasghar Behnamghader ${ }^{3}$ \\ Babak Farsadzadeh' \\ Shahin Bonakdar ${ }^{4}$ \\ 'Department of Biomedical \\ Engineering, Science and Research \\ Branch, Islamic Azad University, \\ Tehran, Iran; ${ }^{2}$ Iran Polymers and \\ Petrochemical Institute, Tehran, Iran; \\ ${ }^{3}$ Materials and Energy Research \\ Center, Tehran, Iran; ${ }^{4}$ National Cell \\ Bank of Iran, Pasteur Institute of Iran, \\ Tehran, Iran
}

\begin{abstract}
Background: Biodegradable polyurethanes have found widespread use in soft tissue engineering due to their suitable mechanical properties and biocompatibility.

Methods: In this study, polyurethane samples were synthesized from polycaprolactone, hexamethylene diisocyanate, and a copolymer of 1,4-butanediol as a chain extender. Polyurethane scaffolds were fabricated by a combination of liquid-liquid phase separation and salt leaching techniques. The effect of the NCO:OH ratio on porosity content and pore morphology was investigated.

Results: Scanning electron micrographs demonstrated that the scaffolds had a regular distribution of interconnected pores, with pore diameters of 50-300 $\mu \mathrm{m}$, and porosities of $64 \%-83 \%$. It was observed that, by increasing the $\mathrm{NCO}: \mathrm{OH}$ ratio, the average pore size, compressive strength, and compressive modulus increased. L929 fibroblast and chondrocytes were cultured on the scaffolds, and all samples exhibited suitable cell attachment and growth, with a high level of biocompatibility.
\end{abstract}

Conclusion: These biodegradable polyurethane scaffolds demonstrate potential for soft tissue engineering applications.

Keywords: polyurethane, tissue engineering, biodegradable, fibroblast cells

\section{Introduction}

Polyurethanes are considered to be excellent biomaterials due to their suitable mechanical properties and good biocompatibility. ${ }^{1-5}$ Resistant polyurethanes have been used as longterm implant materials, including catheters, ${ }^{6}$ artificial heart valves, ${ }^{7}$ wound dressings, angioplasty balloons, ventricular assist devices, and pacing lead insulation. ${ }^{8}$ Recently, investigators have designed biodegradable polyurethanes for applications such as artificial skin, ${ }^{9}$ bone graft substitutes, ${ }^{10}$ drug delivery systems, ${ }^{11}$ and porous scaffolds for regenerating damaged tissues. ${ }^{12}$ The biodegradability and biocompatibility of the polyurethanes are determined by their composition and preparation. ${ }^{13}$ Polyurethanes containing ester or ether groups are vulnerable to degradation through hydrolysis in vivo. ${ }^{14}$

Typically, aliphatic diisocyanate is employed for applications where degradation is desired because its ultimate degradation products are more likely to be nontoxic. Hexamethylenediisocyanate (HMDI), due to its linear structure, is the most widely used isocyanate in the preparation of biodegradable polyurethanes. ${ }^{15-17}$ Polyester polyols, such as polycaprolactone, are amongst the biocompatible and biodegradable polymers used in the synthesis of polyurethanes. The biodegradability of polyurethanes is due to the ester bonds in the polymer structure. ${ }^{18-20}$
Correspondence: Azadeh Asefnejad PO Box 1477893855, Tehran, Iran Tel +98 21 44474321 ext 4 Fax +982144474319

Email asefnejad_azadeh@yahoo.com submit your manuscript $\mid$ www.dovepress.com

Dovepress

http://dx.doi.org//0.2147/IJN.S15586 
Tissue engineering offers an alternative approach to improve, repair, or replace damaged human tissue. It utilizes a combination of progenitor or mature cells to initiate natural tissue repair and regeneration. This process takes place on or within a biomaterial scaffold, and can be done with and without appropriate growth factors. ${ }^{21}$

Briefly, a biomaterial scaffold suitable for use in tissue engineering should be biodegradable and have nontoxic degradation products, be highly porous with an interconnected pore structure, have suitable physical and mechanical properties, and be biocompatible and suitable for cell attachment, proliferation, and differentiation. ${ }^{22}$

Various methods have been investigated for the preparation of porous scaffolds, including electrospinning, ${ }^{23}$ solvent casting/ particulate leaching, ${ }^{24}$ phase inversion, ${ }^{25}$ freeze-drying, ${ }^{26}$ and thermally-induced phase separation. ${ }^{27}$ The solvent casting/salt leaching method has the advantage of controlling pore size by manipulating the size of the salt particulate. Techniques like freeze-drying often allow the fabrication of porous scaffolds with a high compressive modulus. Researchers have used combinations of these techniques to obtain desirable porosity ratios and pore dimensions. ${ }^{25-27}$ In this study, biodegradable linear polyurethanes were prepared using polycaprolactone, HMDI, and 1,4-butanediol/HMDI/1,4-butanediol (BDO/ HMDI/BDO) copolymers. Scaffolds with interconnected porosity were prepared using a combination of salt leaching and freeze-drying methods. The mechanical, morphological, and physical properties of the samples were determined.

The objective of this study was to fabricate a novel polyurethane scaffold by salt leaching and liquid-liquid phase separation. Effects of the NCO:OH ratio on the mechanical, morphological, and physical properties of the scaffolds were also investigated.

\section{Methods and materials}

Polycaprolactone ( $\mathrm{M}_{\mathrm{n}}=2000 \mathrm{~g} / \mathrm{mol}$, Sigma, St Louis, MO) was dried under vacuum for 48 hours, and 1,4-butanediol (Merck, Darmstadt, Germany) and dimethylsulfoxide (Merck) were dried for 24 hours. HMDI (Merck) was distilled under reduced nitrogen pressure prior to use. $\mathrm{NaCl}, 1,4$-dioxane, and dimethyl formamide were used as received from the supplier (Merck).

\section{Prepolymer and polyurethane synthesis}

All reactions were done under nitrogen atmosphere in a glass reactor equipped with a mechanical stirrer. The nitrogen gas, prior to entering the reactor, was dried by passage through concentrated sulfuric acid. The polyurethane was synthesized using a two-step polymerization method (Supplementary Figure S1).
The prepolymers were produced by reacting of polycaprolactone with HMDI for 4 hours at $80^{\circ} \mathrm{C}$. The excess of HMDI was later distilled off under reduced pressure $(0.03 \mathrm{mbar})$ at $80^{\circ} \mathrm{C}$. The stoichiometry of the chemical reaction was $2: 1,4: 1$, and $6: 1$ of HMDI: polycaprolactone. The chain extender copolymer (BDO/HMDI/BDO) was prepared by mixing the HMDI with an excess amount of 1,4-butanediol at $80^{\circ} \mathrm{C}$. The excess of 1,4-butanediol was later removed by washing with acetone. The BDO/HMDI/BDO was dissolved in dimethylsulfoxide and added to the prepolymer at $80^{\circ} \mathrm{C}$ for 30 minutes. The resulting samples from 2:1, 4:1, and 6:1 of HMDI:polycaprolactone were named Polyurethane A1 (PUA1), Polyurethane A2 (PUA2), and Polyurethane A3 (PUA3), respectively. The polyurethane product was washed with water and dried under vacuum at $40^{\circ} \mathrm{C}$. The polyurethane films were prepared by solvent casting of polyurethane solution in dimethylformamide $(5 \% \mathrm{w} / \mathrm{v})$.

\section{Scaffold production}

Polyurethane scaffolds were created by a combination of phase separation and salt leaching techniques. Polyurethane was dissolved in dioxane at a concentration of $20 \%(\mathrm{w} / \mathrm{v})$, and distilled water $5 \%(\mathrm{w} / \mathrm{w})$ was added as a nonsolvent. Pores were created by mixing the solution with $2 \mathrm{~g}$ of $\mathrm{NaCl}$ crystals (varying in size from 50 to $355 \mu \mathrm{m}$ ) per gram of polymer. The polyurethane/salt mixture was poured into several moulds. The filled moulds were rapidly cooled to $-20^{\circ} \mathrm{C}$. Subsequently, the moulds were freeze-dried under vacuum ( $0.1 \mathrm{mbar})$ from -30 to $+5^{\circ} \mathrm{C}$ for 57 hours. The samples were washed for 10 hours in water to remove the salt crystals. The polymer samples were later dried in a vacuum oven for 24 hours at $40^{\circ} \mathrm{C}$ in order to avoid degradation (Table 1).

\section{Material characterization}

\section{Fourier transform infrared spectroscopy}

Infrared data were obtained on $\mathrm{KBr}$ slices with a spectrophotometer (Spectrum One, MB100 series; BOMEM, Minneapolis, $\mathrm{MN})$. Approximately 30 scans were taken for each sample.

\section{Mechanical properties}

The compressive strength of the polyurethane scaffolds was tested using an Instron materials testing machine (Model 1195; Instron Corporation, Norwood, MA) at $23 \pm 2^{\circ} \mathrm{C}$ and relative humidity of $50 \%$. The sample dimensions were $12 \mathrm{~mm} \times 12 \mathrm{~mm} \times 2 \mathrm{~mm}$ and the cross head speed was $2 \mathrm{~mm} / \mathrm{min}$ with a $1000 \mathrm{~N}$ load of cells.

\section{Scaffold porosity}

The porosities of the polyurethane foams were studied using a liquid displacement method similar to the procedure reported 
Table I Mechanical properties of the polyurethane scaffolds

\begin{tabular}{|c|c|c|c|c|c|}
\hline Sample & NCO:OH ratio & Chain extender & Porosity (\%) & Compressive strength ( $\mathrm{MPa})$ & Compressive modulus (MPa) \\
\hline $\begin{array}{l}\text { Polyurethane AI } \\
\text { (PUAI) }\end{array}$ & $2 / 1$ & BDO/HMDI/BDO & $75 \pm 7$ & $0.58 \pm 0.05$ & $0.82 \pm 0.06$ \\
\hline $\begin{array}{l}\text { Polyurethane A2 } \\
\text { (PUA2) }\end{array}$ & $4 / 1$ & BDO/HMDI/BDO & $73 \pm 6$ & $0.71 \pm 0.05$ & $1.17 \pm 0.07$ \\
\hline $\begin{array}{l}\text { Polyurethane A3 } \\
\text { (PUA3) }\end{array}$ & $6 / 1$ & $\mathrm{BDO} / \mathrm{HMDI} / \mathrm{BDO}$ & $71 \pm 7$ & $0.93 \pm 0.08$ & $1.23 \pm 0.11$ \\
\hline
\end{tabular}

Abbreviations: HMDI, hexamethylenediisocyanate; BDO, I,4-butanediol.

by Zhang and $\mathrm{Ma}^{28}$ and Hsu et al. ${ }^{29}$ Ethanol was used as the displacement liquid for this procedure because it penetrated easily into the pores of the polyurethane scaffold. A dry scaffold was placed in a graduated cylinder filled with a predetermined volume (V1) of ethanol, and this cylinder was then placed in a vacuum for 20 minutes to enable penetration of ethanol into the scaffold pores. The total volume of ethanol containing the sample was recorded as V2. The scaffold was taken out of the graduated cylinder, and the residual ethanol volume was recorded as V3. The amount of open pores in the scaffold (P) was calculated according to the following equation:

$$
\mathrm{P}(\%)=(\mathrm{V} 1-\mathrm{V} 3) /(\mathrm{V} 2-\mathrm{V} 3) \times 100 \%
$$

where $(\mathrm{V} 2-\mathrm{V} 3)=$ total volume of the scaffold and $(\mathrm{V} 1-\mathrm{V} 3)=$ volume of ethanol retained in the sample. Three specimens of each sample were used for the porosity measurements and the results were averaged.

\section{In vitro cell culture}

\section{Fibroblast culture}

The cell culture reaction for the prepared films was evaluated by in vitro cell culture testing. Mouse L929 fibroblasts and human dermal fibroblasts isolated from neonatal foreskin (Iran Pasteur Institute, Tehran, Iran) were used in this study and cultured in RPMI containing fetal calf serum $10 \%$, penicillin $100 \mu \mathrm{g} / \mathrm{mL}$, and streptomycin $100 \mu \mathrm{g} / \mathrm{mL}$ (Sigma). A suspension of $1.8 \times 10^{5}$ cells $/ \mathrm{mL}$ was prepared before seeding. Duplicate specimens for each scaffold sample were sterilized in $70 \%$ ethanol and washed in culture medium before the cell culture procedure. The samples were placed on a multiwall polystyrene plate with $5 \mathrm{~mL}$ of cell suspension and maintained for $48 \pm 1$ hours in a $\mathrm{CO}_{2}$-controlled incubator at $37^{\circ} \mathrm{C}$. One sample was retained as a negative control. After incubation, all samples were washed with phosphate-buffered saline solution. The cells were fixed with glutaraldehyde $2.5 \%$ and dehydrated in graded ethanol $(60 \%, 70 \%, 80 \%$, and $95 \%)$. The cells were observed using Nikon light microscopy (Tokyo, Japan). ${ }^{30}$

\section{Chondrocyte culture and isolation}

The scaffold samples were washed with deionized water and sterilized in ethylene oxide gas. Chondrocytes were obtained from the metacarpophangeal joints of 6-9-month-old calves. The samples were put in the bottom of a 24 well-plate, and $0.1 \mathrm{~mL}$ of cell medium suspension at a concentration of $4 \times 10^{6}$ cells $/ \mathrm{mL}$ was added to observe cell attachment. After 2 hours of incubation at $37^{\circ} \mathrm{C}$ and $5 \% \mathrm{CO}_{2}$, the medium (Dulbecco's Modified Eagle Medium, 6\%v/v fetal calf serum) was replaced with $2 \mathrm{~mL}$ of new medium, and the plate was put into the incubator again, under the same conditions. ${ }^{31,32}$ After 3 days of culture, the cells were stained with Trypan Blue. The samples were examined under an optical microscope, and photographs were taken and analyzed.

\section{Cell proliferation assay}

The cell proliferation assay was done according to a previously published method. ${ }^{33}$ The extraction process for the scaffold samples was done according to ISO 10993-5, whereby $1 \mathrm{~mL}$ of RPMI culture medium was added to each sample surface area within a range of $4 \pm 0.5 \mathrm{~cm}^{2}$. After 7 and 14 days, the media samples were removed for use in the cell proliferation assay. A specified amount of culture medium was retained under the same conditions as for the negative control. The proliferation rate of the human fibroblasts exposed to the sample extracts was measured using the 3-(4,5-dimethylthiazol-2-yl)-2,5-diphenyltetrazoliumbromide (MTT) assay (Sigma). The fibroblasts were plated onto a 96-well microtiter plate at $1 \times 10^{4}$ cells/well. After 24 hours, the culture medium of each well was removed and replaced with $90 \mu \mathrm{L}$ of extract plus $10 \mu \mathrm{L}$ of fetal calf serum. The medium was eliminated over the next 24 hours, and $100 \mu \mathrm{L}$ of a MTT $0.5 \mathrm{mg} / \mathrm{mL}$ solution was added to each well, followed by incubation for 5 hours at $37^{\circ} \mathrm{C}$. Purple formazan crystals were dissolved by addition of isopropanol $100 \mu \mathrm{L}$ (Sigma) per well. The plates were then incubated at $37^{\circ} \mathrm{C}$ for 15 minutes prior to absorbance measurements. The optical density was recorded on a multiwell microplate reader 
(ICN, Birsfelden, Switzerland) at $545 \mathrm{~nm}$, and normalized to the control optical density.

\section{Scanning electron microscopy of fibroblasts}

The morphology and pore structure of the porous scaffolds were examined using scanning electron microscopy (440I; LEO, Cambridge, UK). The samples were sputter-coated with gold (approximately $50 \mathrm{~nm}$ ) under vacuum. Scanning electron microscopy was carried out at $15 \mathrm{kV}$. The morphology of human fibroblasts cultured on the samples was also examined by scanning electron microscopy. Cells $\left(5 \times 10^{3}\right)$ were seeded onto the surface of the specimens in a six-well culture plate and incubated using $5 \% \mathrm{CO}_{2}$ at $37^{\circ} \mathrm{C}$ for 7 days. At the end of the culture, the cells were fixed with Karnovsky fixation solution (paraformaldehyde $2 \mathrm{~g}, 25 \%$ glutaraldehyde solution $10 \mathrm{~mL}$, and $0.2 \mathrm{M}$ cacodylate buffer $20 \mathrm{~mL}, \mathrm{pH} 7.4$ ) for 24 hours. Samples were dehydrated in graded alcohols (10\%, 30\%, 50\%, 70\%, 80\%, 85\%, 90\%, 95\%, and 100\%), each for 10 minutes, sputter-coated with gold, and viewed.

\section{Results and discussion}

\section{Fourier transform infrared} spectroscopic analysis

Figure 1 shows the Fourier transform infrared spectrum obtained from the polyurethane samples. The absorption band at $3323 \mathrm{~cm}^{-1}$ corresponds to $\mathrm{NH}$ stretching. The sharp peaks at $2859 \mathrm{~cm}^{-1}$ and $2938 \mathrm{~cm}^{-1}$ are associated with $-\mathrm{CH}_{2}$ stretching, while other modes of $-\mathrm{CH}_{2}$ vibrations are identified by the bands at $1464,1418,1364$, and $1294 \mathrm{~cm}^{-1}$. In addition, the absorption band at $1734 \mathrm{~cm}^{-1}$ is associated with a $\mathrm{C}=\mathrm{O}$ group in polyurethane. The group of $\mathrm{NH}$ vibrations is identified by the bands at $1541 \mathrm{~cm}^{-1}$.

The band at $1702 \mathrm{~cm}^{-1}$ is assigned to hydrogen bonding between $\mathrm{N}-\mathrm{H}$ and $\mathrm{C}=\mathrm{O}$ groups in the hard segment and the ester or ester-oxygen groups of the soft segments of urethane linkage. The band at $1720 \mathrm{~cm}^{-1}$ belongs to nonhydrogen-bonded carbonyl groups (Figure 1). However, on increasing the $\mathrm{NCO}: \mathrm{OH}$ ratios from $2: 1$ to $6: 1$, the intensity of the hydrogen-bonded $\mathrm{C}=\mathrm{O}$ band compared with the nonhydrogen-bonded $\mathrm{C}=\mathrm{O}$ band was increased. ${ }^{26-34}$

\section{Mechanical properties and porosity}

The compressive modulus is an important parameter in tissue formation and thus in the repair of tissue lesions. By changing the ratio of $\mathrm{NCO}: \mathrm{OH}$, the content of the soft segment in polyurethane can be controlled. The mechanical properties of the porous polyurethane scaffolds are shown in Table 1. It can be seen that by increasing the hard segment in the polyurethane scaffold, the compressive strength and compressive modulus also increases. These scaffolds show a compressive strength in the range of $0.58-0.93 \mathrm{MPa}$ and a compressive modulus in the range of $0.82-1.23 \mathrm{MPa}$ (Table 1). It was observed that the less porous scaffolds had better properties.

Increasing the $\mathrm{NCO}: \mathrm{OH}$ ratio in polyurethanes improves their mechanical properties by increasing the uniformity and inter connectivity of the pores. The highest percentage of pores (over 74\%) was observed for the polyurethane A1 scaffold. The average pore size for the sample was about 50-300 $\mu \mathrm{m}$, indicating that the cells could easily penetrate the pores of the scaffold.

\section{Scanning electron microscopy}

The size, distribution, and inter connectivity of the pores determine the capacity of the scaffold to enable cell attachment and growth. Scanning electron photo micrographs of the samples are shown in Figures 2A, 2B, and 2C. These images demonstrate that the scaffolds have porous structures, with pore sizes ranging from $50 \mu \mathrm{m}$ to $300 \mu \mathrm{m}$, which is within the appropriate range for tissue engineering. As can be clearly seen, the pores are rather large, the cell walls are thick, and the pore structure is interconnected. Therefore, cells can penetrate into the pores following their growth on the scaffold surface. Pores were regular, uniformly distributed, and interconnected. Pore content ranged from $64 \%$ to $83 \%$, and the $\mathrm{NCO}: \mathrm{OH}$ ratio decreased at the same time (Table 1). Due to inter connectivity of the pores, the cells could penetrate into the scaffold.

Figure 2D shows electron microscopy images of human fibroblast cells cultured on the polyurethane A3 scaffold. It can be seen that by day 7 , the cells were well grown and spread throughout the polyurethane scaffold. Moreover, fibroblast cell migration into the porous scaffold could be observed in some areas.

\section{Cell culture}

As already reported, ${ }^{27}$ cell adhesion onto a material surface can be arbitrarily classified as a two-step mechanistic process. The first stage is controlled by a complex combination of physicochemical interactions including hydrophobic, coulombic, and Vander Waals forces between the cell membrane and the material surface. This process might be termed "passive adhesion." The second stage might be considered as "active adhesion," because of the participation of metabolic cellular processes. Attached cells are well-known for changing their shapes and expending metabolic energy in order to stabilize the interface between their membranes and the 


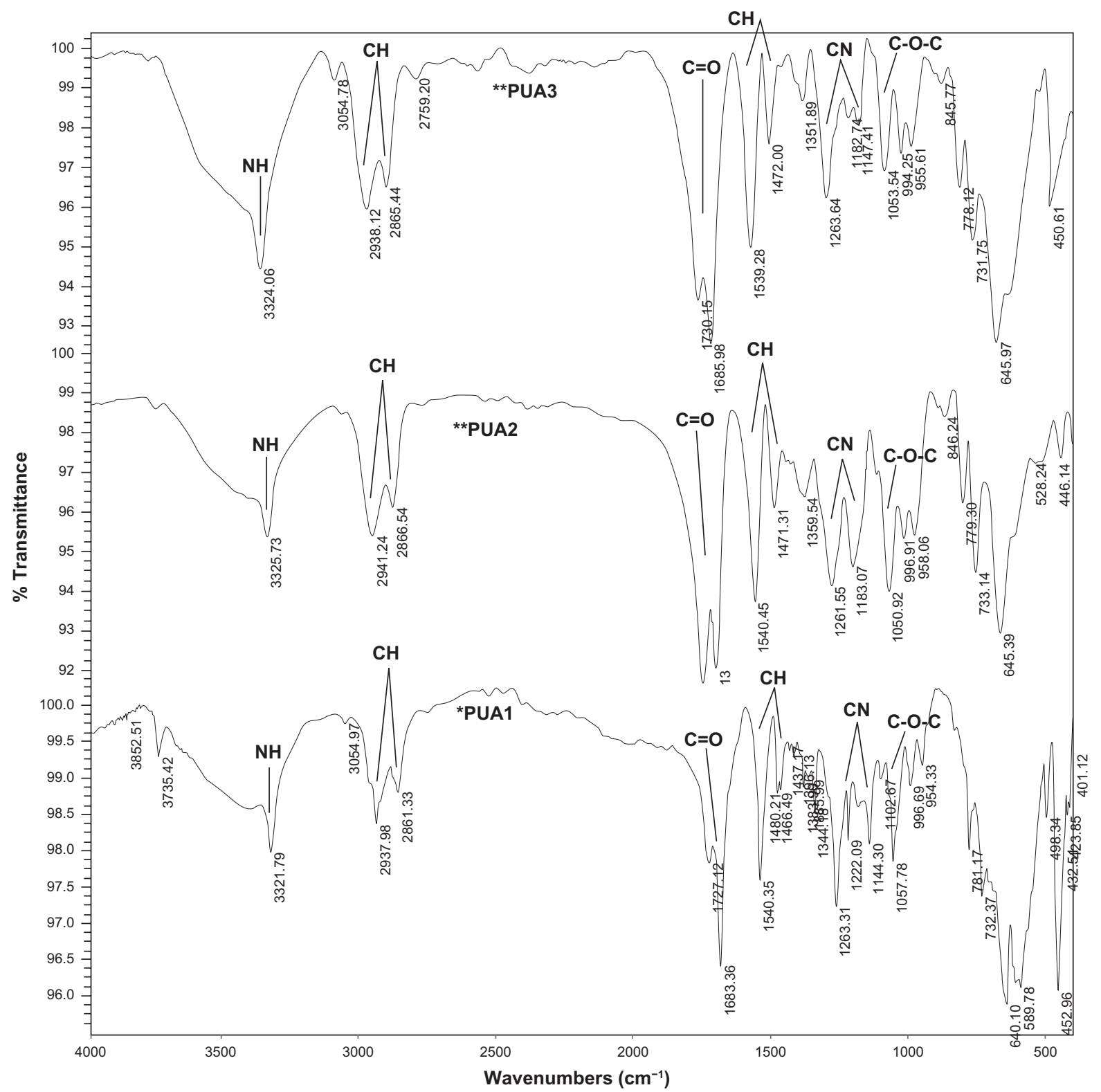

Figure I FTIR spectrum of polyurethane samples.

underlying materials. This could occur by both physicochemical and biological mechanisms.

Figure 3 shows L929 and human fibroblast attachment onto the polyurethane surfaces. The cells showed good proliferation and attachment, and covered the polyurethane surface. Their spreading pattern resembles that of spindle morphology. Apparently what takes place here is active adhesion. L929 and human fibroblasts grew on the polyurethane surfaces and spread on these samples. The cells consumed metabolic energy during this process, which is indicative of active adhesion. These observations strongly suggest that the chemical and/or physical structure of the substrate controls the degree of cell adhesion and proliferation. Our cell culture experiments showed good cell attachment in all the samples, indicating that the scaffolds had a high level of biocompatibility. A suitable cell response was obtained by the 7-day cell seeding procedure (Figure 3). For the polyurethane A3 scaffold, some rounded cells were observed (Figure 3C). Evidence of good attachment is the flattened form of the cells, which was observed in all the samples. A particular substrate is biocompatible if the fibroblast extends more of its body and filopodia onto the surface of the substrate. For the polyurethane A1 scaffold, not only the population of cells attached to the surface but also the quality of their attachment was better than for the other samples (Figure 3A). More cells can be observed in Figure 3B than 

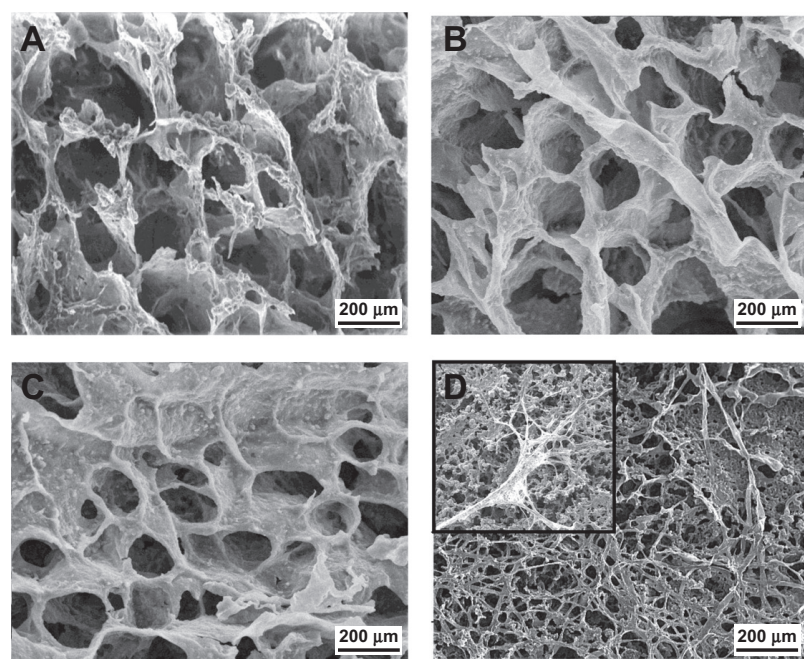

Figure 2 Typical scanning electron microscopy images of polyurethane scaffolds. (A) PUAI; (B) PUA2; (C) PUA3 and (D) SEM of human fibroblasts on polyurethane scaffold after 7 days culture on PUA3.

in Figure 3C. Therefore, it can be concluded that the addition of a soft segment increases the biocompatibility of the scaffold.

The cytotoxicity evaluation shows that the scaffolds had good tissue compatibility with human fibroblast cultures. It was observed that cells cultured in the scaffolds could partially attach, spread, and proliferate in Petri dishes containing
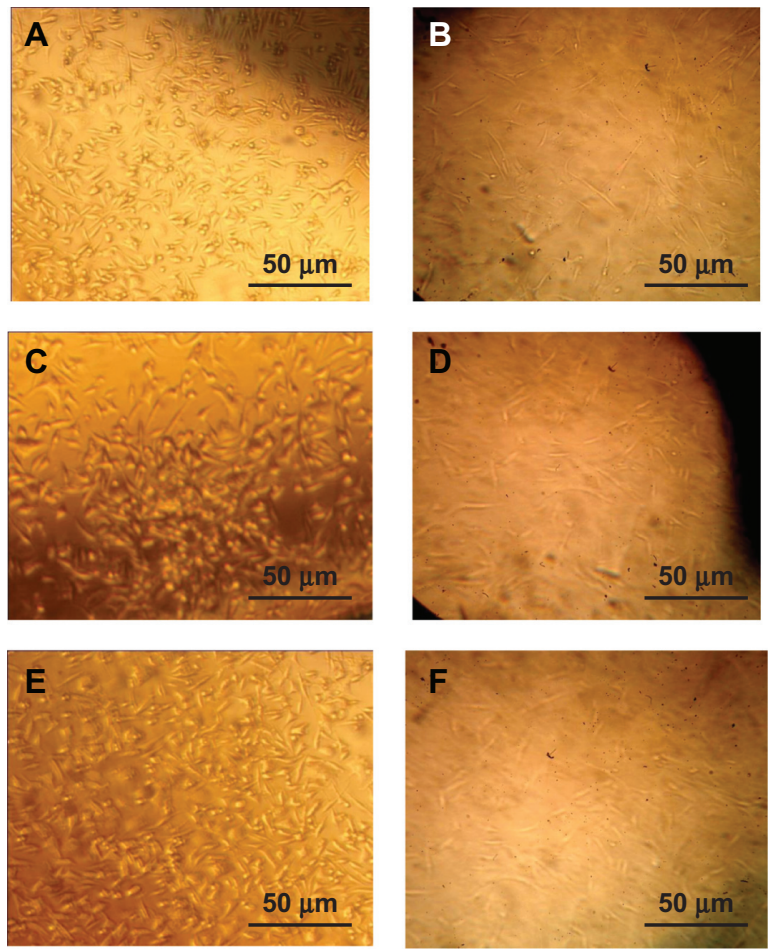

Figure 3 Cell culture of L929 on the (A) PUAI, (B) PUA2, (C) PUA3 (magnification $\times 100$ ) and human dermal fibroblast on (D) PUAI, (E) PUA2, (F) PUA3 (magnification $\times 100$ ).

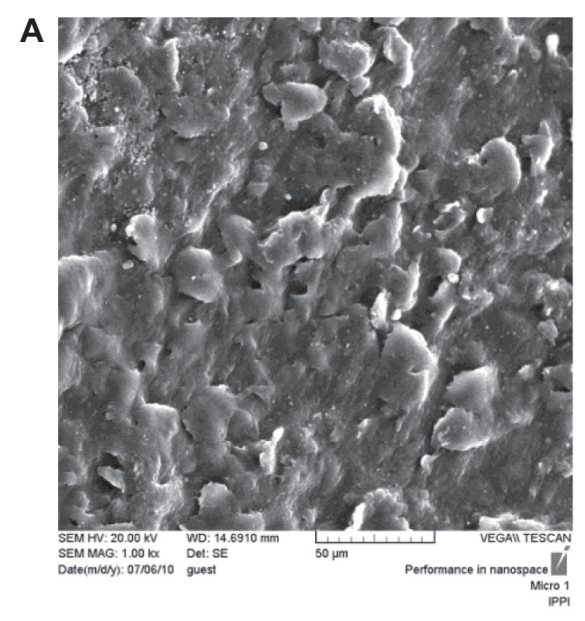

B
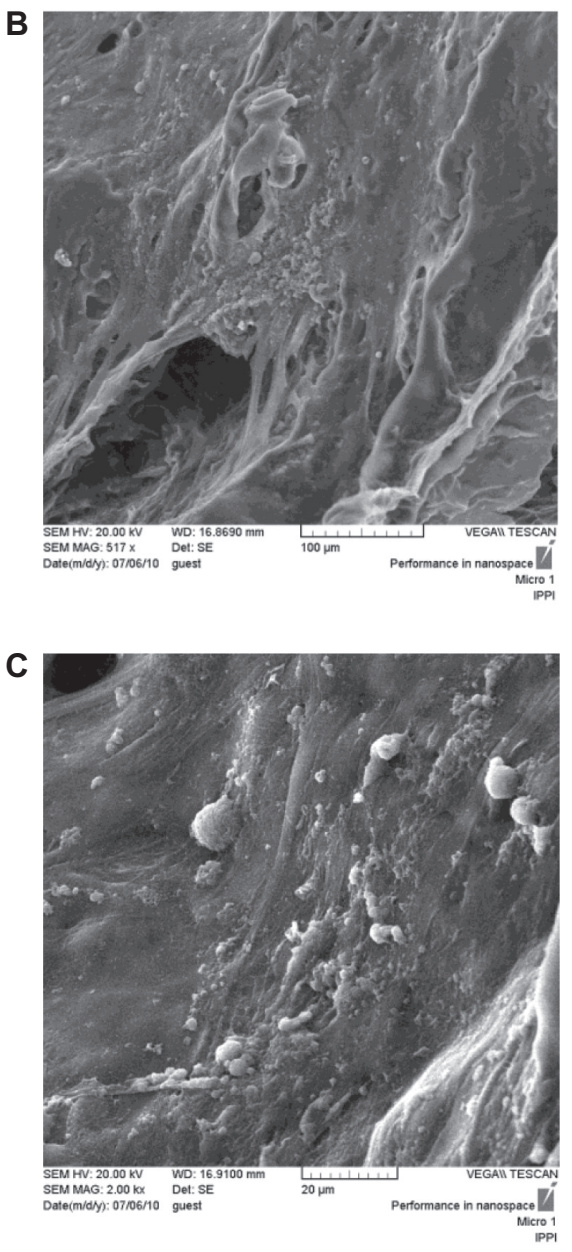

Figure 4 SEM of human fibroblasts on polyurethane scaffold after 7 days in culture (A) PUAI, (B) PUA2, (C) PUA3, The cells well attached on the samples.

samples, and the scaffold surfaces were also covered by fibroblasts (Figures 3D, 3E, and 3F).

Scanning electron microscopic images of human fibroblasts on the different polyurethane scaffold surfaces after 7 days of plating are shown in Figure 4. The cells adhered to and aggregated on the surface and pores of the scaffold. 


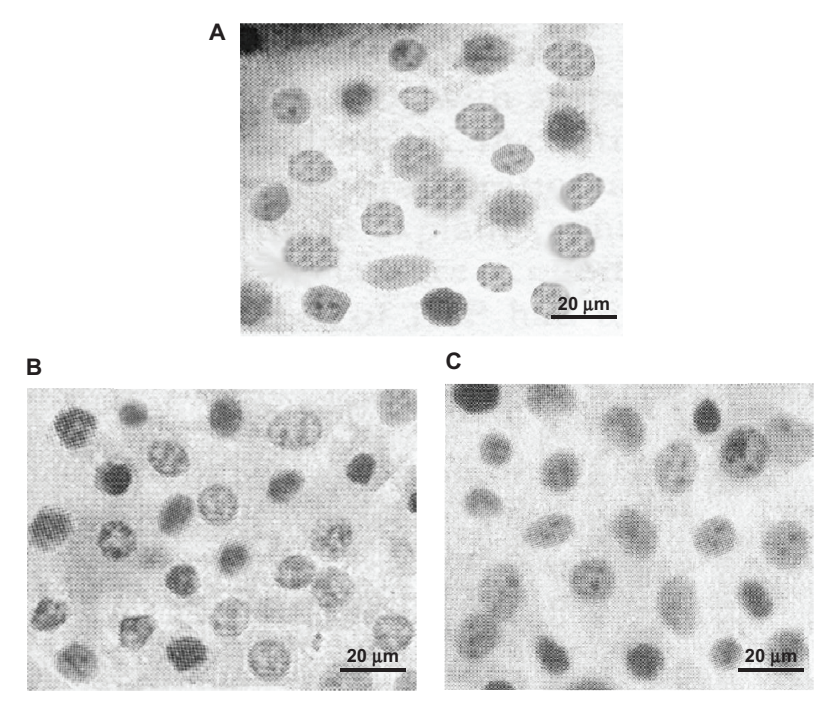

Figure 5 Images of Chondrocytes after 3 days cell culture on polyurethane (A) PUAI, (B) PUA2, (C) PUA3 (magnification $\times 200$ ).
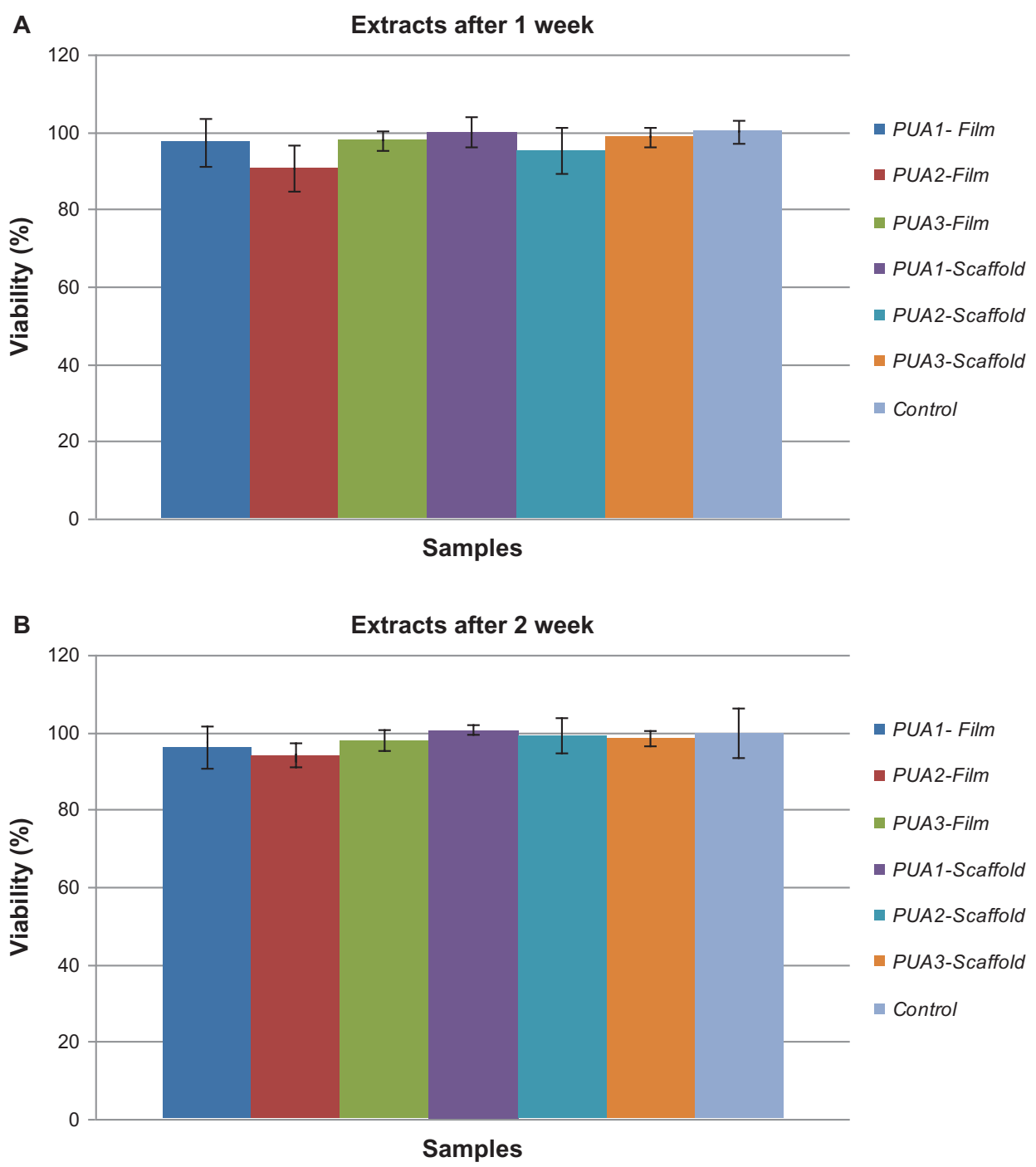

Figure 6 Results of the cell proliferation assay for all samples in comparison with the control: (A) After I weeks, (B) After 2 weeks. 
Fibroblasts displayed good adhesion and spread well on the scaffold samples. However, the morphology of the fibroblasts was varied. Most of the human fibroblasts on the polyurethane scaffolds had more spherical and elongated shapes, and some had a round or flat morphology. The polyurethane A1 scaffold attracted more cells than the polyurethane A2 and A3 scaffolds. The NCO:OH ratio on the polyurethane A1 scaffold was 2:1, so the soft hydrophilic segment on the polyurethane A1 scaffold was greater than in other samples. The cells were attracted to the soft segment, and the polyurethane A1 scaffold showed the best biocompatibility results, as evidenced by a higher attachment rate (Figure 4A). The cell morphology indicates that the polyurethane scaffold is favorable for cell culture.

Analyzing the photographs of chondrocyte culture on the scaffolds indicate that the native phenotype and morphology of the cells was preserved (Figure 5). Therefore, the polyurethane scaffold is suitable for tissue engineering. The results of chondrocyte growth on the scaffold surface indicate that the cells were able to grow without any modification in their morphology and phenotype. Chondrocytes have round shapes, and the images show that the cells attached to the scaffold had similar spherical shapes. These results indicate that biodegradable polyurethane scaffolds have adequatebiocompatibility for use in tissue repair.

\section{Cell proliferation results}

Figure 6 shows the results of the cell proliferation assay for all cells in comparison with controls, and demonstrates that all the samples had cell viability of more than $90 \%$. It seems that increasing the isocyanate groups in the polyurethane composition had no toxic effect on cell viability.

\section{Conclusion}

In this study, biodegradable polyurethane samples were synthesized from polycaprolactone and HMDI, with a copolymer of 1,4-butanediol used as a chain extender. Scaffolds were created by liquid-liquid phase separation and salt leaching techniques. Pores were regular, uniformly distributed, and interconnected. Scanning electron micrographs indicate that the samples had regular and interconnected pores, with sizes in the range of 50-300 $\mu \mathrm{m}$. Fourier transform infraredspectroscopy showed the formation of urethane bonds after polymerization. The compressive strength and compressive modulus of the polyurethane scaffolds increased with increasing $\mathrm{NCO}: \mathrm{OH}$ ratios. These results could be explained by a higher content of hard segments than soft segments in the polyurethane copolymer. The cytotoxicity results showed appropriate cell attachment with a spindle-like spreading pattern. The fibroblasts attached firmly to the surface and pores of the scaffolds, and the polyurethane samples supported attachment and growth of the fibroblasts. The results of in vitro cell culture indicated cell growth on the scaffold surface, and that the cells were able to grow without any modification in their morphology and phenotype. Overall, the results presented here demonstrate that these polyurethane scaffolds are biocompatible.

\section{Acknowledgment}

This work was undertaken with partial financial support from the Islamic Azad University of Science and Research.

\section{Disclosure}

The authors report no conflicts of interest in this work.

\section{References}

1. Spaans CJ, De Groot JH, Belgraver VW, Pennings AJ. A new biomedical polyurethane with a high modulus based on 1,4-butanediisocyanate and E-caprolactone. J Mater Sci Mater Med. 1998;9:675-678.

2. Wetzels GM, Koole H. Photoimmobilisation of poly (N-vinylpyrrolidinone) as a means to improve haemocompatibility of polyurethane biomaterials. Biomaterials. 1999;20:1879-1887.

3. Gorna K, Gogolewski S. Molecular stability, mechanical properties, surface characteristics and sterility of biodegradable polyurethanes treated with low-temperature plasma. Polym Degrad Stab. 2003;79:475-485.

4. Khan I, Smith N, Jones E, Finch DS, Cameron RE. Analysis and evaluation of a biomedical polycarbonate urethane tested in an in vitro study and an ovine arthroplasty model, Part II: in vivo investigation. Biomaterials. 2005;26:633-643.

5. Simmons A, Hyvarinen J, Odell RA, et al. Long-term in vivo biostability of poly(dimethylsiloxane)/poly(hexamethylene oxide) mixed macrodiol-based polyurethane elastomers. Biomaterials. 2004;25: 4887-4900.

6. Park JH, Cho YW, Kwon IC, Jeong SY, Bae YH. Assessment of $\mathrm{PEO} / \mathrm{PTMO}$ multiblock copolymer/segmented polyurethane blends as coating materials for urinary catheters: In vitro bacterial adhesion and encrustation behavior. Biomaterials. 2002;23:3991-4000.

7. Sister VG, Iurechko VN. Experimental study of the hydrodynamics of polyurethane tricuspid heart valves. Med Tekh. 2006;6:8-14. Russian.

8. Stokesa K, Cobiana K. Polyether polyurethanes for implantable pacemaker leads. Biomaterials. 1982;3:225-231.

9. Gogolewski S, Pennings AJ. An artificial skin based on biodegradable mixtures of polylactides and polyurethanes for full thickness skin wound covering. Makromol Chem Rapid Commun. 1983;4:675-680.

10. Gogolewski S, Gorna K. Biodegradable polyurethane cancellous bone graft substitutes in the treatment of iliac crest defects. J Biomed Mater Res A. 2006;80A:94-101.

11. Sivak WN, Pollack IF, Petoud S, Zamboni WC, Zhang J, Beckman EJ. Catalyst-dependent drug loading of LDI-glycerol polyurethane foams leads to differing controlled release profiles. Acta Biomater. 2008;4: $1263-1274$.

12. Gogolewski S, Gorna K, Zaczynska E, Czarny A. Structure-property relations and cytotoxicity of isosorbide-based biodegradable polyurethane scaffolds. J Biomed Mater Res A. 2007;85A:456-465.

13. Gunatillake P, Mayadunne R, Adhikari R. Recent developments in biodegradable synthetic polymers. Biotechnol Annu Rev. 2006; 12:301-347.

14. Darby RT, Kaplan AM. Fungal susceptibility of polyurethanes. Appl Microbiol. 1968;16:900-905. 
15. Tuominen J, Kylmä J, Kapanen A, Venelampi O, Itävaara M, Seppälä J. Biodegradation of lactic acid based polymers under controlled composting conditions and evaluation of the ecotoxicological impact. Biomacromolecules. 2002;3:445-455.

16. Gorona K, Gogolewski S. Novel biodegradable polyurethanes for medical applications. American Society of Testing and Materials. 2000:39-57.

17. Lamba N, Woodhouse K, Cooper S. Polyurethanes in Biomedical Applications. New York: CRC Press; 1998.

18. Gorona K, Gogolewski S. Biodegradable polyurethanes for implants. II. In-vitro degradation and calcification of materials from poly( $\varepsilon$-caprolactone)-poly(ethylene oxide) diols and various chain extenders. J Biomed Mater Res. 2002;60:592-606.

19. Walinska K, Iwan A, Gorna K, Gogolewski S. The use of long-chain plant polyprenols as a means to modify the biological properties of new biodegradable polyurethane scaffolds for tissue engineering: A pilot study. J Mater Sci Mater Med. 2008;19:129-135.

20. Gorona K, Gogolewski S. In vitro degradation of novel medical biodegradable aliphatic polyurethanes based on $\varepsilon$-caprolactone and Pluronics with various hydrophilicities. Polym Degrad Stab. 2002;75: 113-122.

21. Yang XB, Webb D, Blaker J, et al. Evaluation of human bone marrow stromal cell growth on biodegradable polymer/bioglass composites. Biochem Biophys Res Commun. 2006;342:1098-1107.

22. Spaans CJ, Belgraver VW, Rienstra O, de Groot JH, Veth RP, Pennings AJ. Solvent-free fabrication of micro-porous polyurethane amide and polyurethane-urea scaffolds for repair and replacement of the knee-joint meniscus. Biomaterials. 2000;21:2453-2460.

23. Rockwood DN, Woodhouse KA, Fromstein JD, Chase DB, Rabolt JF. Characterization of biodegradable polyurethane microfibers for tissue engineering. J Biomater Sci Polym Ed. 2007;18:743-758.

24. Fromstein JD, Woodhouse KA. Elastomeric biodegradable polyurethane blends for soft tissue applications. J Biomater Sci Polym Ed. 2002; 13:391-406.
25. Savarino L, Baldini N, Greco M, et al. The performance of poly- $\varepsilon$ caprolactone scaffolds in a rabbit femur model with and without autologous stromal cells and BMP4. Biomaterials. 2007;28:3101-3109.

26. Gerçek I, Tigli RS, Gümüsderelioglu M. A novel scaffold based on formation and agglomeration of PCL microbeads by freeze-drying. JBiomed Mater Res A. 2008;86:1012-1022.

27. Saad B, Matter S, Ciardelli G, et al. Interactions of osteoblasts and macrophages with biodegradable and highly porous polyesterurethane foam and its degradation products. J Biomed Mater Res. 1996;32:355-366.

28. Zhang RY, Ma PX. Poly(a-hydroxyl acids)/hydroxyapatite porous composites for bone-tissue engineering. I. Preparation and morphology. $J$ Biomed Mater Res. 1999;44:446-455.

29. Hsu YY, Gresser JD, Trantolo DJ, Lyons CM, Gangadharam PR, Wise DL. Effect of polymer foam morphology and density on kinetics of in vitro controlled release of isoniazid from compressed foam matrices. J Biomed Mater Res. 1997;35:107-116.

30. Khorasani MT, Mirzadeh H. BHK cells behaviour on laser treated polydimethylsiloxane surface. Colloids Surf B Biointerfaces. 2004;35: 67-71.

31. Karbasi S, Mirzadeh H, Orang F, Urban JPG. A comparison between cell viability of chondrocytes on a biodegradable polyester urethane scaffold and alginate beads in different oxygen tension and $\mathrm{pH}$. Iran Polym J. 2005;14:823-830.

32. Yang L, Korom S, Weder W. Tissue-engineered cartilage generated for human trachea using Degrapol scaffold. Eur J Cardiothorac Surg. 2003;24:201-207.

33. Bonakdar S, Hojjati Emami S, Shokrgozar MA, et al. Preparation and characterization of polyvinyl alcohol hydrogels crosslinked by biodegradable polyurethane for tissue engineering of cartilage. Mater Sci Eng C Mater Biol Appl. 2010;30:636-643.

34. Kurimoto Y, Takeda M, Koizumi A, Yamauchi S, Doi S, Tamura Y. Mechanical properties of polyurethane films prepared from liquefied wood with polymeric MDI. Bioresour Technol. 2000;74:151-157. 


\title{
Supplementary figure
}

\author{
$2 \mathrm{O}=\mathrm{C}=\mathrm{N}-\mathrm{R}-\mathrm{N}=\mathrm{C}=\mathrm{O}+\mathrm{HO}-\left(\mathrm{R}^{\prime}\right)_{\mathrm{n}}-\mathrm{OH} \quad \longrightarrow \mathrm{O}=\mathrm{C}=\mathrm{N}-\mathrm{R}-\mathrm{NH}-\mathrm{CO}-\mathrm{O}-\left(\mathrm{R}^{\prime}\right)_{\mathrm{n}}-\mathrm{O}-\mathrm{OC}-\mathrm{HN}-\mathrm{R}-\mathrm{N}=\mathrm{C}=\mathrm{O}$ \\ Diisocyanate (HMDI) Polycaprolacton diol (PCL) Prepolymer
}

$\mathrm{O}=\mathrm{C}=\mathrm{N}-\mathrm{R}-\mathrm{NH}-\mathrm{CO}-\mathrm{O}-\left(\mathrm{R}^{\prime}\right)_{\mathrm{n}}-\mathrm{O}-\mathrm{OC}-\mathrm{HN}-\mathrm{R}-\mathrm{N}=\mathrm{C}=\mathrm{O}+\mathrm{HO}-\left(\mathrm{R}^{\prime \prime}\right)_{\mathrm{n}}-\mathrm{O}-\mathrm{OC}-\mathrm{NH}-\mathrm{R}-\mathrm{NH}-\mathrm{CO}-\mathrm{O}-\left(\mathrm{R}^{\prime}\right)_{\mathrm{n}}-\mathrm{OH} \longrightarrow$

Prepolymer Chain extender

- [- O- $\left.\left(R^{\prime \prime}\right)_{n}-\mathrm{O}-\mathrm{OC}-\mathrm{NH}-\mathrm{R}-\mathrm{NH}-\mathrm{CO}-\mathrm{O}-\left(\mathrm{R}^{\prime}\right)_{\mathrm{n}}-\mathrm{O}-\mathrm{OC}-\mathrm{N}-\mathrm{R}-\mathrm{NH}-\mathrm{CO}-\mathrm{O}-\left(\mathrm{R}^{\prime \prime}\right)_{\mathrm{n}}-\mathrm{O}-\right]_{x}-$

\section{Polyurethane}

Figure SI Polyurethane synthesis.

\section{Publish your work in this journal}

The International Journal of Nanomedicine is an international, peerreviewed journal focusing on the application of nanotechnology in diagnostics, therapeutics, and drug delivery systems throughout the biomedical field. This journal is indexed on PubMed Central, MedLine, CAS, SciSearch ${ }^{\circledR}$, Current Contents ${ }^{\circledR} /$ Clinical Medicine,
Journal Citation Reports/Science Edition, EMBase, Scopus and the Elsevier Bibliographic databases. The manuscript management system is completely online and includes a very quick and fair peer-review system, which is all easy to use. Visit http://www.dovepress.com/ testimonials.php to read real quotes from published authors. 